\title{
Effectiveness of Pulmonary Rehabilitation in Lymphangioleiomyomatosis
}

\author{
Manivel Arumugam, Senthil Dhanasekaran'1, Kancherla Roopa', Pitchaimani Govindharaj² \\ Department of Pulmonary Medicine, Pulmonary Rehabilitation Unit, PSG Institute of Medical Sciences and Research, PSG Hospitals, ${ }^{1}$ Department of Pulmonary \\ Medicine, PSG Institute of Medical Sciences and Research, PSG Hospitals, Coimbatore, ${ }^{2}$ Department of Allied Health Sciences, Sri Ramachandra Institute of Higher \\ Education and Research (DU), Chennai, Tamil Nadu, India
}

\section{Abstract}

Lymphangioleiomyomatosis (LAM) is a cystic lung disease frequently associated with reduced exercise capacity, mostly affecting young women. The disease is characterized by progressive pulmonary cystic change, recurrent pneumothorax, chylous pleural collections, and in most cases, progressive respiratory failure. Diagnosis is made by a combination of clinical features and computed tomography scanning or, with lung biopsy. We present a case report of a young woman who suspected of LAM and diagnosed with cystic lung disease, admitted to the intensive care unit in view of worsening hypoxia associated with pneumothorax. She was on ventilator support and placement of repeated intercostal drains and had a tracheostomy to step down to bilevel positive airway pressure support, after the medical stabilization. She was referred for pulmonary rehabilitation, in which she showed good outcomes and recovered well.

Keywords: Hormonal therapy, lymphangioleiomyomatosis, pulmonary rehabilitation

\section{INTRODUCTION}

Lymphangioleiomyomatosis (LAM) is a rare disease of the lungs and lymphatics, which can occur sporadically or in association with tuberous sclerosis. LAM almost exclusively affects young women, generally developing before menopause. The disease is characterized by progressive pulmonary cystic changes with the accumulation of LAM cells, recurrent pneumothorax, and chylous pleural collections and, in most cases, progressive respiratory failure. ${ }^{[1]}$ Along with chest $\mathrm{X}$-ray changes (pneumothorax and effusions), high resolution computed tomography (HRCT) findings of multiple, small, diffusely distributed cysts, an elevated serum vascular endothelial growth factor-D (VEGF-D) testing are the most diagnostic measures. Lung biopsy is indicated only when HRCT findings and VEGF-D testing are nondiagnostic. ${ }^{[2]}$

Most patients with LAM complain of impaired quality of life and reduced exercise capacity, secondary to airflow obstruction, abnormal diffusion capacity, dynamic hyperinflation, peripheral muscle dysfunction (deconditioning), and pulmonary hypertension. ${ }^{[3]}$ Available medical management like Sirolimus and hormonal therapy (Medroxyprogesterone,

\begin{tabular}{|l|l|}
\hline \multicolumn{2}{|c|}{ Access this article online } \\
\hline Quick Response Code: & Website: \\
\hline & www.ijrc.in \\
\hline & \\
\hline
\end{tabular}

Gonadotropin-releasing hormone agonists) may slow down disease progression; however, the disease remains incurable. Pulmonary rehabilitation (PR) is a safe intervention and improves exercise capacity, dyspnea, daily physical activity, muscle strength, and quality of life in LAM. ${ }^{[4,5]}$ After obtaining appropriate consent from the patient, we present a case report of a young female patient who suspected of LAM and diagnosed with cystic lung disease and the outcomes of PR.

\section{Case Report}

A 25-year-old female, health-care worker, reported to the emergency room with sudden onset of breathlessness and hypoxemic shock. In view of worsening conditions, she was shifted to the intensive care unit (ICU) and intubated with

Address for correspondence: Mr. Manivel Arumugam, Senior Physiotherapist-Grade-II, Department of Pulmonary Medicine, Pulmonary Rehabilitation Unit, PSG Institute of Medical Sciences and Research, PSG Hospitals, Coimbatore - 641 004, Tamil Nadu, India. E-mail: arumani_005@yahoo.co.in

This is an open access journal, and articles are distributed under the terms of the Creative Commons Attribution-NonCommercial-ShareAlike 4.0 License, which allows others to remix, tweak, and build upon the work non-commercially, as long as appropriate credit is given and the new creations are licensed under the identical terms.

For reprints contact:WKHLRPMedknow_reprints@wolterskluwer.com

How to cite this article: Arumugam M, Dhanasekaran S, Roopa K, Govindharaj P. Effectiveness of pulmonary rehabilitation in lymphangioleiomyomatosis. Indian J Respir Care 2021;10:252-6.

Received: $30-08-2020$ Accepted: $21-10-2020$ Published: 14-06-2021 
mechanical ventilation. Initial chest X-ray [Figure 1a] showed a bilateral pneumothorax with subcutaneous emphysema and it was treated by bilateral intercostals drainage (ICD). There was persistent air leak for a prolonged duration, along with inadequate lung expansion. Initial HRCT-chest [Figure 2a and $2 \mathrm{c}$ ] showed extensive fibro-bronchiectatic changes with few cystic changes noted in bilateral lower lobes and also bronchopleural fistula (BPF). Since she was diagnosed with pulmonary tuberculosis 3 months ago with sputum positive (sputum Gene expert positive, Rifampicin sensitive), and she was started on treatment; however, Ziehl-Neelsen stain was negative after the 3 months. She had developed multiple episodes of nosocomial infection during the period of ICU. It was treated with appropriate antibiotics, and infection settled down. Repeated blood and tracheal cultures were sterile; however, her respiratory distress persisted due to recurrent pneumothorax.

A repeat HRCT-thorax was done, which showed extensive bilateral cystic changes with a right-sided loculated pneumothorax with 2 ICDs in situ on the right side and one on the left side, and very poor lung reserve. A possible diagnosis of Sporadic LAM was suspected with HRCT; hence cardiothoracic surgeon opinion was obtained for open lung biopsy but deferred in view of high risk. Autologous blood patch was attempted twice to seal the BPF but was a failure. In view of the difficulty in weaning from the ventilator, tracheostomy was done after 2 weeks. In view of constant ICD site pain, thoracic epidural analgesia was given. Gradually, she was weaned off the ventilator and was maintained on bilevel positive airway pressure support.

In view of possible LAM, high dose of medroxyprogesterone and doxycycline were administered with informed consent. Gradually bilateral air leak stopped, and bilateral ICDs were removed. The repeated chest X-rays [Figure 1b-d] and HRCT [Figure $2 \mathrm{~b}$ and $2 \mathrm{~d}$ ] showed multiple cysts with surrounding multiple large bullae replacing the left upper

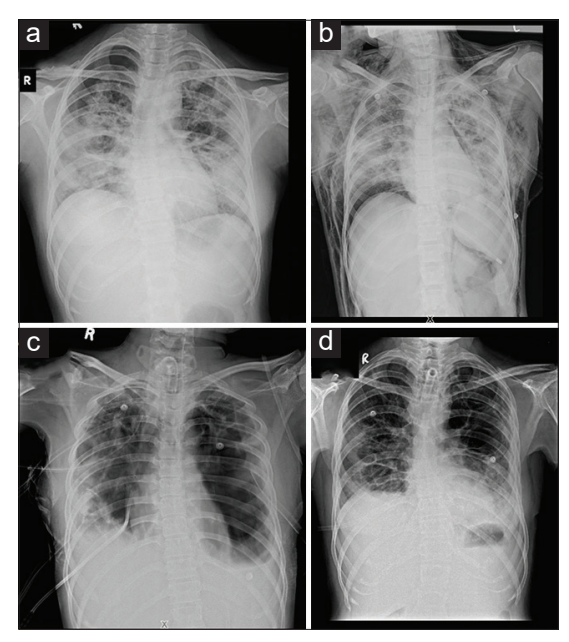

Figure 1: (a) Initial chest X-ray before admission. (b) During admission repeated chest X-rays. (c) After 1 month of hormone treatment. (d) At the time of discharge lobe sparing the lingular segment-bulla have increased in size. Multiple cysts in the right upper lobe, right middle lobe, and anterior right lower lobe. Cysts have increased in size/ parenchymal strands, small areas of pneumonitis in the right lower lobe and upper lobe [Figure 2c].

Due to prolonged ICU stays along with worsened disease condition, she developed ICU acquired critical illness myoneuropathy, and systemic deconditioning associated with proximal muscle atrophy. With the low lung reserve and cystic lung disease, the team planned and advised her family to get ready for lung transplantation. Meanwhile, PR was initiated to achieve fitness for surgery. Hence, she was enrolled in PR program with exercise-based intervention. Nutritional status was improved with dietary correction and psychological support was given, which helped her to come out of her anxiety.

\section{Pulmonary rehabilitation program}

The PR program was initiated after getting informed consent. PR program was conducted with two interventional programs; ICU-based intervention, and inpatient. The ICU-based intervention outcomes were measured by using the Standardized 5 Questions (S5Q) for assessing patients' ability to cooperate, Modified Medical Research scores for muscle strength, and Berg Balance Scale for balance. The ICU based intervention was started with the use of the Leuven protocol from "start to move." "[ It is a six-level assessment and treatment protocol, which includes basic assessment of S5Q (1). Open and close your eyes, (2). Look at me, (3). Open your mouth and stick out your tongue, (4). Shake yes and no nod your head, (5). I will count to 5, frown your eyebrows) and Modified Medical Research score $(0=$ no visible contraction, $1=$ visible contraction without limb movements, 2 = movements of the limb in the eliminated gravity, $3=$ movement against gravity

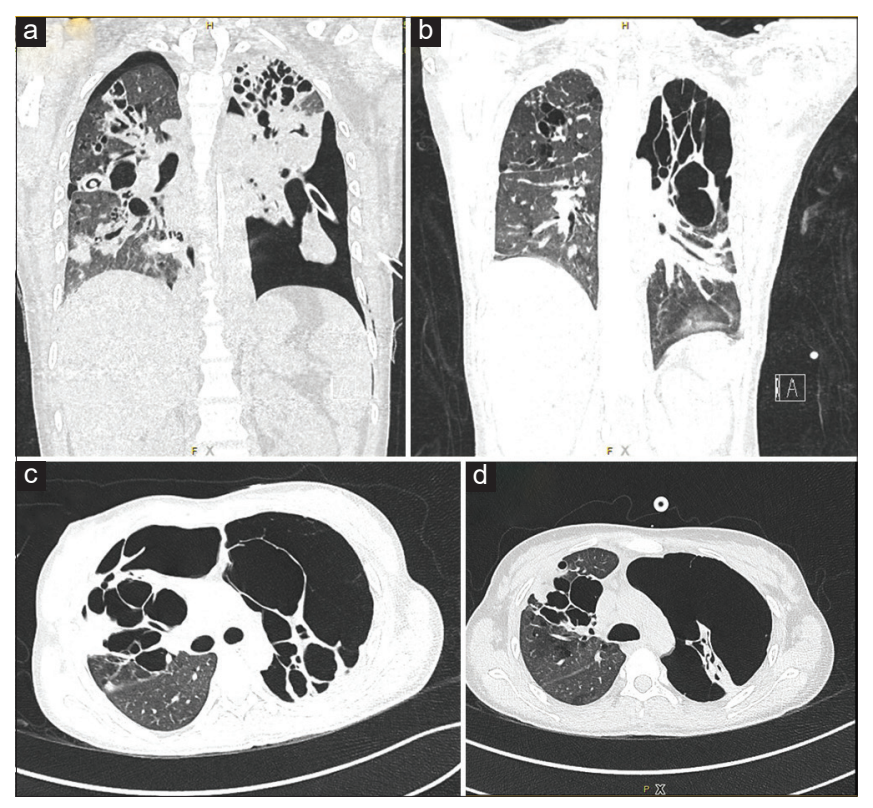

Figure 2: (a) Initial high resolution computed tomography-chest at the time of admission. (b) At the time of discharge. (c) After 1 month of hormone treatment. (d) At the time of discharge 
in full range, $4=$ movement against gravity with resistance, $5=$ normal strength). If the patient passed in S5Q then go for muscle strength test (muscles to be tested deltoid, biceps, wrist extensors, quadriceps, dorsiflexors, and the total score; 60 if the score $<48 / 60$-significant muscle weakness). Berg balance scale components include sitting with back unsupported but feet supported on the floor, sitting to standing, standing unsupported (scores from 0 -unable to do for $10 \mathrm{~s}$ to 4 -able to do for 2 min comfortably). According to this assessment, the treatment protocol was administered in ICU and explained in Table 1.

In-patient PR program was initiated after shifting to the ward. Baseline assessment was collected. It was followed by $1 \mathrm{~min}$ sit to stand test, 6 min walk test, ${ }^{[7]}$ activity questionnaire's functional independence measure (score; self-care domain), which includes eating, grooming, bathing, dressing upper and lower body and toileting (scoring starts with 1-total assistance to 7-complete independence), physical activity index (which includes poor to high active category) and modified sphygmomanometer, ${ }^{[8]}$ was used to the measured hand grip. The PR program consists of exercise training (flexibility training, endurance training, strength training, airway clearance technique, and breathing retraining), educational support (about her condition, program, nutrition, advantages, and guidance to family members), psychological counseling, and nutritional intervention as per need. The detailed PR program is explained in Table 1. The PR program was continued from the day shifted from ICU and 4-6 days/week to till discharge (4 weeks). Home care program was advised to do regular exercises such as

\section{Table 1: Protocol of pulmonary rehabilitation program}

\section{Phase I: ICU based Intervention started after hemodynamic stability (6 weeks)}

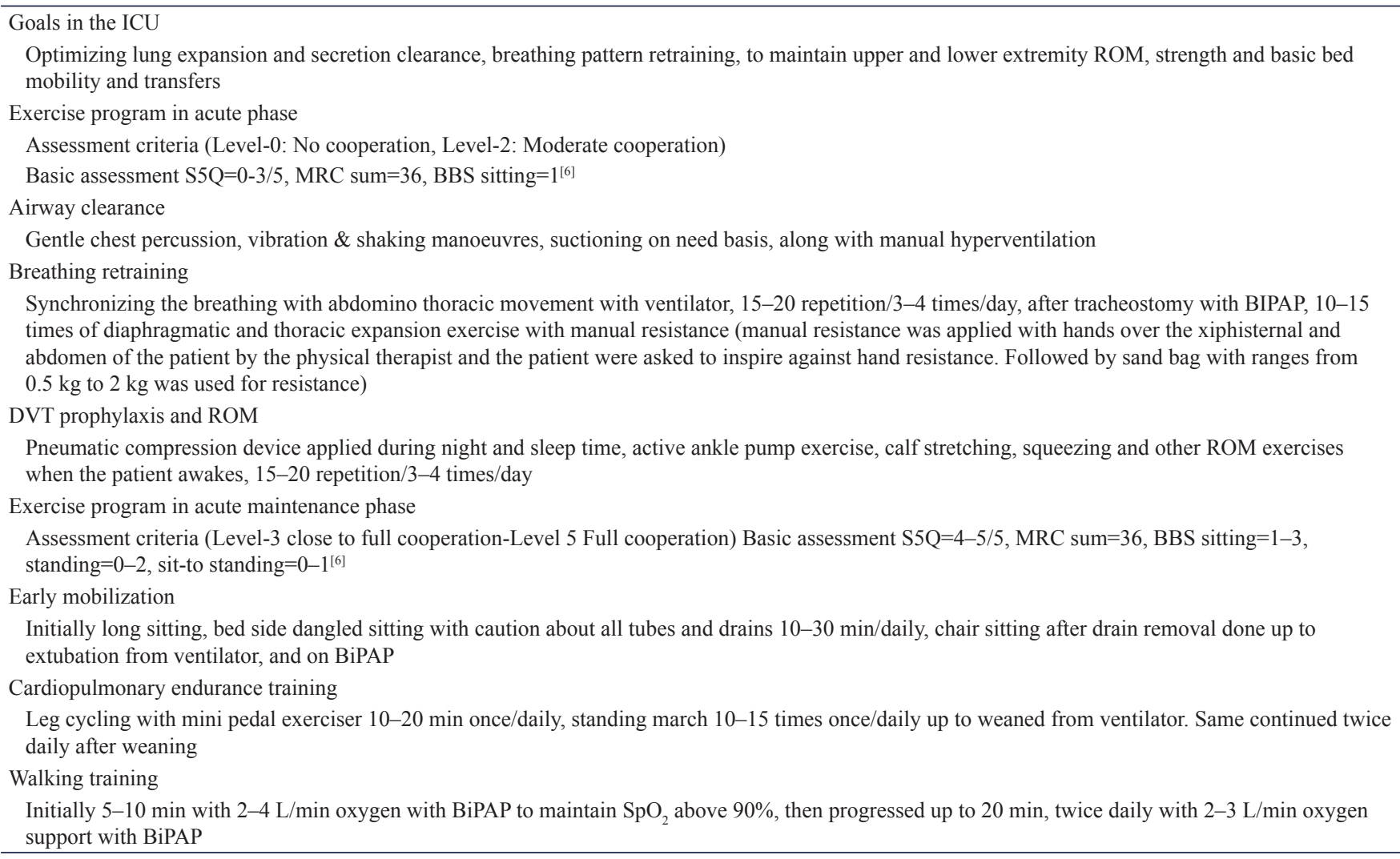

\section{Phase II: Inpatient rehabilitation program till discharge, 5-6 days/week (4 weeks)}

\footnotetext{
Endurance training

Level walking as much as tolerated (10-20 min, according to patients walking speed or with 6MWT distance or intensity of modified Borg scale 4-6/10). Arm and leg cycle ergo meter: 10-20 min/5-6 weekly. Borg's scale 4-6/10

Strength training

Target muscles trained with dumbbells, weight cuffs (up to 2 weeks we avoided upper limb weight lifting due to repeated pig tail and ICD insertion) Upper limb: Biceps, triceps, deltoid, pectorals. Lower limb: quadriceps, hamstrings, gluteus muscles, calf and dorsi flexors with $1-3 \mathrm{~kg} / 10 \mathrm{rep} / 2 \mathrm{sets} /$ alternate days

Breathing retraining exercises

Breathing control through diaphragmatic breathing and localized thoracic expansion exercise with $15-20$ rep/2-3 h once, trained breathing exercise in sitting, semi Fowler's position and side lying and supine gradually, paced breathing was trained during activities

S5Q: Standardized 5 questions, MRC: Medical research council score for muscle testing, BBS: Berg's Balance score, BiPAP: Bi-level Positive airway pressure, ICD: Intercostals drainage, 6MWT: 6-min walk test, ROM: Range of motion, ICU: Intensive care unit, DVT: Deep-vein thrombosis
} 


\begin{tabular}{|c|c|c|c|c|c|}
\hline \multirow[t]{2}{*}{ Outcome measures } & \multirow{2}{*}{$\begin{array}{l}\text { Initial assessment } \\
\text { in ICU }\end{array}$} & \multicolumn{4}{|c|}{ During inpatient rehabilitation (4 weeks) } \\
\hline & & First & Second & Third & Fourth \\
\hline \multicolumn{6}{|l|}{ Anthropometric parameters } \\
\hline Height (cm) & 157 & & & & \\
\hline Weight $(\mathrm{kg})$ & 32.6 & 36.4 & 38.5 & 39.7 & 40.4 \\
\hline $\operatorname{BMI}\left(\mathrm{kg} / \mathrm{m}^{2}\right)$ & 13.23 & 14.77 & 15.62 & 16.11 & 16.39 \\
\hline Hand grip (mm of $\mathrm{Hg}$ ) & R15 and L12 & R30 and L25 & R40 and L35 & R45 and L40 & R60 and L55 \\
\hline 6-min walk distance & - & $120 \mathrm{~m}(20.01 \%)$ & $160 \mathrm{~m}(26.87 \%)$ & $220 \mathrm{~m}(37.11 \%)$ & $280 \mathrm{~m}(47.35 \%)$ \\
\hline 1 minute sit to stand & 3 times $/ \mathrm{min}$ & 10 times $/ \mathrm{min}$ & 18 times $/ \mathrm{min}$ & 26 times $/ \mathrm{min}$ & 30 times $/ \mathrm{min}$ \\
\hline Berg balance score ( 3 domains) & $1 / 12$ & $8 / 12$ & $10 / 12$ & $12 / 12$ & $12 / 12$ \\
\hline $\mathrm{SpO}_{2} \%$ desaturation during & $-8(98-90)$ & $-6(96-90 \%)$ & $-3(98-95)$ & $-3(98-95)$ & $-3(98-95)$ \\
\hline activities & $40 \% \mathrm{FiO}_{2}$ & $28 \% \mathrm{FiO}_{2}$ & $4 \mathrm{l} / \mathrm{min} \mathrm{O}_{2}$ & $4 \mathrm{l} / \mathrm{min} \mathrm{O}_{2}$ & Room air \\
\hline$\Delta$ Heart rate & $\begin{array}{c}24 \text { beats } \\
(120-154 \text { beats } / \mathrm{min})\end{array}$ & $\begin{array}{c}22 \text { beats } \\
(126-148 \text { beats } / \mathrm{min})\end{array}$ & $\begin{array}{c}34 \text { beats } \\
(118-152 \text { beats/min) }\end{array}$ & $\begin{array}{c}24 \text { beats } \\
(130-154 \text { beats/min }\end{array}$ & $\begin{array}{c}34 \text { beats } \\
(130-164 \text { beats/min) }\end{array}$ \\
\hline Modified Borg scale & $7 / 10$ & $5 / 10$ & $4 / 10$ & $3 / 10$ & $3 / 10$ \\
\hline FIM scale (Self-care domain) & $6 / 42(14 \%)$ & $11 / 42(26 \%)$ & $24 / 42(57 \%)$ & $30 / 42(71 \%)$ & $33 / 42(78.5 \%)$ \\
\hline & Maximal assistance & Maximal assistance & Moderate assistance & Minimal assistance & Supervision \\
\hline PAI & 6 (sedentary) & $\begin{array}{l}36 \text { (poor, not good } \\
\text { enough) }\end{array}$ & 48 (fair, acceptable) & $\begin{array}{l}64 \text { (very good, } \\
\text { active, and healthy) }\end{array}$ & $\begin{array}{l}80 \text { (very active } \\
\text { lifestyle) }\end{array}$ \\
\hline \multicolumn{6}{|l|}{ ABG } \\
\hline $\mathrm{pH}$ & 7.268 & 7.44 & 7.387 & 7.39 & 7.48 \\
\hline $\mathrm{FiO}_{2}(\%)$ & 21 & 45 & 40 & 35 & 21 \\
\hline $\mathrm{PCO}_{2}(\mathrm{mmHg})$ & 64.1 & 47 & 52.4 & 56.0 & 29.3 \\
\hline $\mathrm{PaO}_{2}(\mathrm{mmHg})$ & 62.4 & 71.5 & 72.5 & 80.8 & 74.1 \\
\hline $\mathrm{HCO}_{3}(\mathrm{mEq} \mathrm{l} / \mathrm{L})$ & 22.7 & 95.2 & 30.8 & 33.8 & 22.0 \\
\hline $\mathrm{SaO}_{2}(\%)$ & 89.7 & 31.5 & 94.4 & 96.1 & 95.2 \\
\hline Lactate $(\mathrm{mmol} / \mathrm{L})$ & 4.60 & 1.23 & 1.55 & 1.1 & 1.0 \\
\hline
\end{tabular}

FIM: Functional independence measure, BMI: Body mass index, PAI: Physical activity index, ABGs: Arterial blood gases, ICU: Intensive care unit

walking, breathing exercises, resistance exercises with the use of simple object such as water bottles and sandbags. Outcome measures are explained in Table 2.

\section{DISCUSSION}

Our patient showed significant improvements in exercise performance and quality of life following PR from day one to till discharge. Initially, the patients were hopeless towards exercise-based intervention due to long-term ventilation, repeated ICD tubes insertion, painful events during procedures, being transferred for different tests such as computed tomography and long-term ICU stay. Repeated psychological counseling, and appropriate hormone therapy with medroxyprogesterone and doxycycline the symptoms of pneumothorax and air leaks in ICDs were settled, along with adjustment of analgesics the graded mobilization was initiated. She accepted the changes and gave her full effort during the sessions. Initially, she was mobilized with maximal assistance then reduced to supervised mobilization; initially, she could participate 15-30 min in exercise sessions, while before discharge, she tolerated up to $2 \mathrm{~h}$. She had showed a noticeable improvement in exercise capacity, observed in both endurance exercise time, during walking, reducing the level of dyspnea, increased daily physical activity, enhanced muscle strength, and improved quality of life. A positive trend toward symptoms of depression was also observed. The program was safe, well-tolerated and had a high rate of adherence. Her family members also showed high interest during the PR sessions and advised to follow the same at home.

This report clearly shows the importance and benefit of a PR program, even though it shows changes in patient recovery from physical illness rather than the disease state. PR program can be a good adjunct therapy to pharmacological treatment. In addition, serves as a bridging aid before lung transplantation in such chronic respiratory diseases such as LAM.

\section{Financial support and sponsorship}

Nil.

\section{Conflicts of interest}

There are no conflicts of interest.

\section{ReFERENCES}

1. Johnson SR, Tattersfield AE. Decline in lung function in lymphangioleiomyomatosis: relation to menopause and progesterone treatment. Am J Respir Crit Care Med 1999;160:628-33.

2. McCormack FX, Gupta N, Finlay GR, Young LR, Taveira-DaSilva AM, Glasgow CG, et al. Official American Thoracic Society/ Japanese Respiratory Society clinical practice guidelines: Lymphangioleiomyomatosis diagnosis and management. Am J Respir Crit Care Med 2016;194:748-61. 
3. Baldi BG, Albuquerque AL, Pimenta SP, Salge JM, Kairalla RA, Carvalho CR. Exercise performance and dynamic hyperinflation in lymphangioleiomyomatosis. Am J Respir Crit Care Med 2012;186:341-8

4. Araujo MS, Baldi BG, Freitas CS, Albuquerque AL, Marques da Silva CC, Kairalla RA, et al. Pulmonary rehabilitation in lymphangioleiomyomatosis: A controlled clinical trial. Eur Respir J 2016;47:1452-60.

5. Gloeckl R, Nell C, Schneeberger T, Jaroschi I, Boensch M, Watz H, et al. Benefits of pulmonary rehabilitation in patients with severe lymphangioleiomyomatosis: Improving our practice: Novel approaches to pulmonary rehabilitation/poster discussion. Am J Respir Crit Care Med 2020;201:A6120.

6. Gosselink R, Clerckx B, Robbeets C, Vanhullebusch T, Vanpee G, Segers J, et al. Physiotherapy in the intensive care unit. Neth J Crit Care. 2011;15:66-7.

7. Palaniappan Ramanathan R, Chandrasekaran B. Reference equations for 6-min walk test in healthy Indian subjects (25-80 years). Lung India 2014;31:35-8.

8. Chandrasekaran B, Ghosh A, Prasad C, Krishnan K, Chandrasharma B. Age and anthropometric traits predict handgrip strength in healthy normals. J Hand Microsurg 2010;2:58-61. 